\title{
linking individual value orientations to employee attitudes: an exploratory analysis
}

\author{
Zhou Jiang
}

\begin{abstract}
This study tested the relationships of individualism, power distance, and mastery orientation to 2 employee attitudes (organizational trust and organizational commitment) that are associated with employees' psychological benefits within the organization. Results from university employees $(N=706)$ showed that individualism negatively, whereas mastery positively, related to trust and commitment. Power distance positively related to trust only. The moderating role of mastery was also identified. These findings can help employment or organizational counselors to appreciate value-related factors that facilitate employees in psychologically integrating into the organization and to explore new ways for employers to foster employees' positive attitudes.
\end{abstract}

Keywords: individualism, power distance, mastery, organizational trust, organizational commitment

Individual cultural values are important at work, as evidenced by the growing body of research that shows that values affect employees' perceptions, cognitions, selfconcepts, well-being, and attitudes (Shao, Rupp, Skarlicki, \& Jones, 2013; Taras, Kirkman, \& Steel, 2010). This line of research has contributed significantly to employment and management research by developing practical strategies for managing employees with different personal values. However, researchers (e.g., Kirkman, Lowe, \& Gibson, 2006) contend that these strategies will remain underdeveloped until sufficient empirical evidence is gathered to form relatively stable patterns of the effects of cultural values on employees' psychological reactions, particularly on employee attitudes. Extended and fine-grained explorations of the value-attitude relationships are important to foster scholarly, managerial, and counseling heuristics, which are difficult to draw from the extant research.

In response to calls from previous researchers (Clugston, Howell, \& Dorfman, 2000; Gelfand, Erez, \& Aycan, 2007; Kirkman et al., 2006; Taras et al., 2010),

Zhou Jiang, Department of Employment Relations and Human Resources, Griffith University, Nathan, Queensland, Australia. Zhou Jiang is now at Department of Management, Deakin University, Geelong, Victoria, Australia. Earlier versions of this article were reviewed and presented in August 2015 at the annual meeting of the Academy of Management in Vancouver, British Columbia, Canada, and in December 2014 at the annual conference of the Australian and New Zealand Academy of Management in Sydney, New South Wales, Australia. Correspondence concerning this article should be addressed to Zhou Jiang, Department of Management, Deakin Business School, Deakin University, Locked Bag 20000, Geelong, Victoria 3220, Australia (email: dr.zhou.jiang @gmail.com). 
the present study extends this area by investigating the relationships of individual value orientations with organizational trust and commitment, and the interactive effects of value orientations on these employee attitudes. The literature indicates that the development processes of trust- and commitment-based attitudes toward the organization are accompanied by the formation of psychological comfort individuals perceive at associated stages of employment (Allen \& Meyer, 1990; Evanschitzky, Iyer, Plassmann, Niessing, \& Meffert, 2006). With this informed perspective, studying the roles of value orientations in shaping trust and commitment can help employment counselors gain new insights to facilitate employees' integration into the organization in a psychologically comfortable (e.g., trust and commitment based) manner. The present study follows an emerging trend (e.g., Farh, Hackett, \& Liang, 2007; Kirkman \& Shapiro, 2001; Schilpzand, Martins, Kirkman, Lowe, \& Chen, 2013) to test cultural value orientations at the individual level (rather than the country or societal level). This consideration is based on the fact that when the country is used as a proxy variable, there is no way of capturing individual cultural differences (Schilpzand et al., 2013); moreover, employees' attitudes at the workplace tend to be more closely related to their individual beliefs than the beliefs endorsed at the country level (Kirkman et al., 2006). As such, country is not a key variable in the main analyses in the current study.

One major limitation in the literature is that most culture-related organizational research examines values from a single cultural model (Clugston et al., 2000; Randall, 1993; Shao et al., 2013). However, culture is formed in the social interaction process, characterizing basic values, beliefs, norms, assumptions, and attitudes among human beings (Lytle, Brett, Barsness, Tinsley, \& Janssens, 1995); this process has led to the emergence of different models that conceptualize culture (Hofstede, 1980; House, Hanges, Javidan, Dorfman, \& Gupta, 2004; Kluckhohn \& Strodtbeck, 1961). These models overlap theoretically, but more important, they also supplement each other (Maznevski, Gomez, DiStefano, Noorderhaven, \& Wu, 2002). Examples of such supplementation have been reflected in studies of employee outcomes that combined cultural constructs from different models/perspectives (e.g., Farh et al., 2007; Fischer \& Mansell, 2009; Kirkman \& Shapiro, 2001). However, the small amount of research does not capture the majority of gaps or overlap between cultural models, given the complexity of culture (Jiang, Gollan, \& Brooks, 2015). As Gelfand et al. (2007) argued, this complexity cannot be fully understood without studying multiple values simultaneously and examining neglected sources of differences in cultural values.

The present study examined Hofstede's (1980) model of individualism and power distance and Kluckhohn and Strodtbeck's (1961) model of mastery orientation. These two cultural models are used because Hofstede's model is the dominant model in management discipline (Kirkman et al., 2006), and Kluckhohn and Strodtbeck's model addresses the most fundamental problems and has contributed to the development of many later models (Maznevski et al., 2002; Yeganeh \& Su, 2011). Both models have been verified to be operationalizable at the individual level (e.g., Clugston et al., 2000; Maznevski et al., 2002), although Hofstede's model was originally developed from the societal level. At the individual level, individualism refers to a 
person's tendency to value his or her interests more than the group's welfare; power distance reflects one's tendency to accept power differences and to value personal status (Clugston et al., 2000; Dorfman \& Howell, 1988); and mastery orientation denotes an individual's tendency to exert control over his or her environment and outside forces (Jiang, 2015; Maznevski et al., 2002). The present study focuses on this set of values because they reflect Triandis's (1993) ideology that culture is a group strategy for survival that comprises continuous attempts to adapt to external environments. This cultural ideology involves two main components: interpersonal relationships associated with groups and attitudes toward the environment. Whereas individualism and power distance characterize relationships among people within or between groups, mastery orientation emphasizes one's beliefs of, and attitudes toward, a broader environment (Maznevski et al., 2002). Although human relation-oriented and environment-oriented cultural values have been found to affect work-related attitudes (Kirkman \& Shapiro, 2001), no studies have examined individualism, power distance, and mastery simultaneously in investigating the effects of cultural values on work attitudes.

Another limitation in the literature is the lack of exploration of how different cultural values (and particularly values from different cultural frameworks) interact to influence employee attitudes (Gelfand et al., 2007; Kirkman et al., 2006). Examining moderating or interactive variables is valuable, because it promotes the establishment of boundary conditions for cultural value effects, thus facilitating the understanding and interpretation of research findings and assisting practitioners in identifying the situations in which cultural values may be more/less powerful in influencing organizationally relevant outcomes (Taras et al., 2010). According to Meglino and Ravlin (1998), situational variables tend to alter the effects of human-oriented values. Given that mastery is closely related to the nature of environments and situations, the present study also aims to examine how mastery can moderate the effects of the human relation-focused values (i.e., individualism and power distance) on employee attitudes. Such an investigation of the interactive effects of cultural values from distinct theoretical models can contribute to the identification of intracorrelated structures of culture.

The present study examined trust and commitment because they are two important work attitudes related to interpersonal and relationship interactions (Allen \& Meyer, 1990; Schoorman, Mayer, \& Davis, 2007), which are regarded as attributes of cultural orientation (Maznevski et al., 2002; Triandis, 1993). As stated earlier, some psychologically beneficial attributes of trust and commitment may help generate counseling and managerial implications for analyzing employees' psychological states (e.g., sense of comfort, positive feelings and attitudes) during employment (Allen \& Meyer, 1990) from a value orientation perspective. To make the findings relatively generalizable, this study focused on a multicultural context involving three Asia Pacific countries_China, South Korea, and Australia — that include both Eastern and Western cultures. This study uses a multicultural sample to explore (a) the impact of individualism, power distance, and mastery on organizational trust and commitment and (b) the moderating role of mastery in the relationships of individualism and power distance to trust and commitment, respectively. 


\section{INDIVIDUALISM, POWER DISTANCE, AND EMPLOYEE ATTITUDES}

According to Fischer and Mansell (2009), the concept of individualism-collectivism underlies the essence of commitment by addressing cultural norms and processes regarding individual and group relationships and explaining whether and why people commit to their groups. Boyacigiller and Adler (1991) argued that the commitment of collectivists (i.e., people with low individualism) arises from interpersonal ties within the organization, whereas individualists' commitment is more directly related to the job itself or reward systems. Because collectivists are driven by group ties, values, goals, and interests, they tend to more naturally identify with their associated groups, such as a work organization, than their high-individualism counterparts. These characteristics of individualism may also be logically extended to other organization-oriented attitudes such as trust in the organization, given that trust, similar to commitment, is also a relationshipfocused employee attitude (Chathoth, Mak, Sim, Jauhari, \& Manaktola, 2011; Schoorman et al., 2007).

Power distance underscores the appropriate relationships and differences in status between people from different hierarchies, which, like individualism, can also help ascertain why people might feel emotionally attached to an organization (Fischer \& Mansell, 2009). Employees with higher power distance generally accept their relative positions and statuses that are differentiated by hierarchy and readily submit to authority (Clugston et al., 2000; Hofstede, 1980). Although situations with power hierarchies and top-down decision making may reduce employees' affective commitment and trust in the organization (Kirkman \& Shapiro, 2001), the values and natural tendencies of employees with high power distance confer upon them greater tolerance and acceptance of such asymmetric situations (Hofstede, 1980). However, employees with low power distance, having less tolerance of power inequalities, may regard such situations as unfavorable and unacceptable and are thus less likely to exhibit positive attitudes toward the organization. In addition, Farh et al. (2007) indicated that employees with lower power distance rely more on social exchange ideology and reciprocity norms. Because of greater sensitivity to the organization's conduct, they are more likely to criticize power inequalities, which may occur in every organization because power discrepancies are fundamental to every individual and perhaps to every human group (Hofstede $\&$ Bond, 1988). Therefore, employees with low power distance expect social exchange and reciprocity but are more likely to find that reality deviates from their expectations. This conflict may raise more concerns and cause employees to have less positive attitudes that reflect social exchange quality, such as trust and commitment (Colquitt et al., 2013). Therefore,

Hypothesis 1. Individualism is negatively related to trust (Hypothesis 1a) and commitment (Hypothesis 1b).

Hypothesis 2. Power distance is positively related to trust (Hypothesis 2a) and commitment (Hypothesis 2b). 


\section{MASTERY AND EMPLOYEE ATTITUDES}

Mastery is a cultural component drawn from Kluckhohn and Strodbeck's (1961) value orientation model, which complements and serves as the foundation of many other models (e.g., Hofstede, 1980; House et al., 2004). According to research that highlights mastery from a cultural perspective (e.g., Jiang, 2015; Yeganeh \& Su, 2011), one core effect of mastery is that it contributes to people's confidence and reduces psychological stress and concerns in work and career settings, thus increasing their tendency to actively take risks at work (Lysaker et al., 2011). As stated previously, employees' commitment to and trust in their organization are built on their exchanges with the organization. Commitment and trust theories suggest that a risk-taking tendency is an essential driver for developing and maintaining these exchange relationships, because relationship building involves uncertain and risky situations that may hinder employees' emotional attachment to and trust in their employers (Colquitt, Scott, \& LePine, 2007). According to Koller (1988), when individuals perceive that they are able to control situations, they tend to be more involved in risky interpersonal situations and are more likely to actively contribute to committed and trusting relationships.

Because mastery is characterized as the value orientation governing proactive control over situational and environmental forces (Jiang, 2015), it might be considered an individual attribute that assists in reducing perceptions of risk in certain situations and that benefits the levels of employee commitment and trust. For example, people high on mastery tend to have greater self-confidence in managing outside forces in their associated environments, such as work settings, to create positive changes in their environment to meet their desired goals. In contrast, people low on mastery tend to believe that these forces (e.g., the organization's policies and decisions) are beyond their personal control, which may raise psychological concerns about whether positive outcomes can be attained. These concerns may prevent low-mastery employees from showing trust and committing to the organization despite wanting to maintain a harmonious relationship in their job environment (Jiang et al., 2015). Thus, it is argued that high-mastery employees, compared with their low-mastery counterparts, have a greater propensity to trust in and commit to their organizations. Therefore,

Hypothesis 3. Mastery is positively related to trust (Hypothesis 3a) and commitment (Hypothesis 3b).

\section{MODERATING ROLE OF MASTERY}

Although prior research suggests that cultural values can interact to influence work-related outcomes (Sivakumar \& Nakata, 2001), studies examining these interaction effects are remarkably rare (Kirkman et al., 2006). Because the few observable cases focus mainly on Hofstede's (1980) cultural dimensions, such as individualism and power distance (Sivakumar \& Nakata, 2001), Kirkman et al. 
(2006) suggested that it is important to explore a wider range of cultural values in relation to the interaction effect. The present study proposes that individuals' environmental values can intervene in the effects of human relation-oriented values on employees' attitudes.

Viewing mastery as an environment- and situation-related human factor (Jiang et al., 2015), this article draws upon trait activation theory (Tett \& Burnett, 2003) to examine how mastery can alter the influence of individualism and power distance on employee attitudes (e.g., trust and commitment). Trait activation theory proposes that environment-related factors can activate individuals' traits and make the effects of these traits on human attitudes and behaviors more salient. Research indicates that these factors can extend to people's perceptions, cognitions, judgments, tendencies, and other psychological states related to the environment (Tett \& Burnett, 2003). As mastery value orientation is specifically environment/situation related (Maznevski et al., 2002), it can be expected to be a trait activator. From a trait perspective, power distance and individualism are regarded by some scholars (e.g., Botero \& Van Dyne, 2009) as individual traits that are logically relevant to external forces such as power discrepancies and social connections, which are usually driven by the systems and institutions of organizations (Jiang et al., 2015). As stated earlier, the two individual values (power distance and individualism) that reflect employees' beliefs about and orientations toward these external factors will matter in developing employee attitudes.

Applying this thinking, power distance and individualism may lead to greater difference in employee attitudes when employees rely more on environmental or situational forces. Low-mastery individuals, believing that outside forces cannot be controlled or completely changed, tend to embrace fatalism (Finch, Shanahan, Mortimer, \& Ryu, 1991) and rely on harmonious relationships, expecting their concerns and distress caused by outside forces to be balanced by these relationships (Jiang et al., 2015). This tendency leads them to care about the equilibrium between the self and the environment and to place greater importance on external (e.g., organizational structure and hierarchy) than internal (e.g., one's own motivation to make changes) forces. Therefore, the attitudes (e.g., trust and commitment) of low-mastery people may be more susceptible to be influenced by their own values underlying these forces (e.g., power discrepancies and social connections in the organization). In other words, lower mastery is more likely to activate power distance and individualism and make them salient-with greater influence on employee attitudes.

On the other hand, the self-confidence and control orientation of high-mastery employees tend to lead them to perceive more favorable aspects of work environments, because they believe that outside forces are manageable (Jiang et al., 2015). Because of this internally driven self-efficacy in self-determining their own outcomes, high-mastery employees' preferences and acceptance of power (in)differences (e.g., power distance) and interpersonal (in)dependence (e.g., individualism-collectivism) might not be as influential as those held by low-mastery employees. This means that higher mastery is less likely to activate power distance and individualism, and thus their influences on trust and commitment might be less salient. Therefore, 
Hypothesis 4. Mastery moderates the relationships of individualism with trust (Hypothesis 4a) and commitment (Hypothesis 4b), such that these relationships are stronger when mastery is low rather than high.

Hypothesis 5. Mastery moderates the relationships of power distance with trust (Hypothesis 5a) and commitment (Hypothesis 5b), such that these relationships are stronger when mastery is low rather than high.

\section{METHOD}

\section{Participants and Procedure}

A total of 706 employees from 65 universities in Australia, South Korea, and China participated in this study. These three Asia Pacific countries include both dramatically different (e.g., Australia vs. China) and highly analogous (i.e., China vs. South Korea) cultures that are characterized by a range of work-related values and preferences (Hofstede, 1980). The university context was chosen because it has been argued that universities play important roles in the development and transmission of cultural values (Chatterton, 2000). University employees, particularly educators, are considered embodiments of cultural values that contribute significantly to value socialization (Schwartz, 1992). Chinese universities were identified through professional and personal networks. Australian universities were randomly ranked and successively identified from the ranking list until the number of usable surveys reached over 200, which is recommended as an ideal country sample size for confirmatory factor analysis (CFA; Kline, 2010) and meets Israel's (1992) minimal standard for a good sample size for regression analyses. A similar procedure was used when identifying Korean universities.

Prior to survey administration, the originally developed questionnaire was translated from English to Korean, and then back-translated from Korean to English, independently by two different translators (Brislin, 1980). The translated version was also checked by two other bilingual proofreaders. The same approach was used to develop the Chinese questionnaire. An email invitation, which included a web link for the online survey, was sent to the Australian and Korean participants. Paper surveys were distributed to Chinese participants during working hours. Response rates for Australia (10.7\%) and China (46.6\%) were consistent with the ranges identified in Shih and Fan's (2008) meta-analyses for web and mail surveys, respectively. Although the response rate for South Korea $(4.2 \%)$ was rather low, it was comparable with the response rate of several previous studies that used online surveys (e.g., Lederer, Maupin, Sena, \& Zhuang, 2000). To further alleviate this concern, the present study used Armstrong and Overton's (1977) procedure, which had been used by numerous researchers (e.g., Li, Chen, Liu, \& Peng, 2014) to rule out nonresponse biases. The results are highly unlikely to be biased if no significant differences exist in study variables between early and late responses (Armstrong \& Overton, 1977; Li et al., 2014). The present research followed Parente, Baack, and Hahn (2011) in considering the first $70 \%$ of returned surveys as early responses and the other $30 \%$ 
as late responses. $T$ tests were conducted to compare all study variables between early and late groups. Because no early-late differences were found for any variable in any of the three countries at $p<.05$, nonresponse bias would not be a significant issue in this study. The composition of the sample $(N=706)$ was as follows: 237 Australians (33.57\%), 242 Koreans (34.28\%), and 227 Chinese (32.15\%); 383 men (54.25\%); 610 full-time employees (86.40\%); and 539 academic workers $(76.35 \%)$. The participants had an average age of 43 years and an average tenure of 8 years. More than half $(n=380,53.82 \%)$ held a PhD degree.

\section{Measures}

Individualism. Dorfman and Howell's (1988) six-item scale was used to measure individualism-collectivism at the individual level. Example items include "Employees should only pursue their goals after considering the welfare of the group" and "Individuals may be expected to give up their goals in order to benefit group success." Because individualism and collectivism are at opposite ends of a continuum, all scores for individualism items were reverse coded (Clugston et al., 2000; Dorfman \& Howell, 1988).

Power distance. Dorfman and Howell's (1988) six-item scale was used to measure power distance at the individual level. Example items include "Managers should avoid off-the-job social contacts with employees" and "Employees should not disagree with management decisions."

Mastery orientation. Maznevski and DiStefano's (1995) seven-item measure was used to assess mastery orientation. Example items include "Good performance comes from taking control of one's business" and "With enough knowledge and resources, any poor performing business can be turned around." One item was dropped from analysis to improve the scale reliability significantly for the Korean and Chinese samples and also for the full sample.

Organizational trust. Six items from Robinson (1996) that reflect Gabarro and Athos's (1976) trust dimensions were used to measure employees' trust in their organization. Example items include "I can expect my employer to treat me in a consistent and predictable fashion" and "I believe my employer has high integrity."

Organizational commitment. Meyer, Allen, and Smith's (1993) six-item scale was used to measure employees' affective commitment to the organization. Example items include "I would be very happy to spend the rest of my career with this organization" and "This organization has a great deal of personal meaning for me."

\section{RESULTS}

Before the hypotheses were tested, CFA and the Harman's single-factor test were conducted using AMOS 20.0 (maximum likelihood estimation) for the measurement model. Following Hofstetter and Cohen's (2014) recommendations and strategy, I used item parceling to reduce indicators for multi-item constructs in CFA. In accordance with the procedure outlined in the literature (e.g., Brooke, Russell, \& Price, 1988), 
CFA was first performed for each of the five constructs. The average score of the items with lowest and highest loadings was used as the first indicator, followed by that of the items with second lowest and second highest loadings, and so forth until all items were assigned to an indicator (Aryee, Budhwar, \& Chen, 2002; Hofstetter \& Cohen, 2014). Finally, three indicators were created for each of the five constructs. This strategy was necessary because it could reduce the number of estimated parameters in testing measurement models and reduce inflated measurement errors resulting from multiple items of latent variables (Hofstetter \& Cohen, 2014).

The CFA results demonstrated that the five-factor model, $\chi^{2}(80)=328.90, \chi^{2} /$ $d f=4.11$, root-mean-square error of approximation $(\mathrm{RMSEA})=.70$, standardized root-mean-square residual $(\mathrm{SRMR})=.05$, and comparative fit index $(\mathrm{CFI})=.96$, fit the data well, with all its fit indexes showing much better fit compared with the single-factor model, $\chi^{2}(90)=2,944.70, \chi^{2} / d f=37.72, \mathrm{RMSEA}=.21$, SRMR $=.17$, and CFI $=.49$. The chi-square difference test further supported that the five-factor model fit the data significantly better than did the single-factor model, $\Delta \chi^{2}(10)=$ $2,615.80, p<.001$, suggesting that common method bias was not a significant issue (Podsakoff, MacKenzie, Lee, \& Podsakoff, 2003).

Given the importance of the cross-cultural equivalence of the measures in the present study, multigroup CFA was performed to test the configural and metric invariance models, as adopted by Kim, Weber, Leung, and Muramoto (2010). Whereas configural invariance reflects that the pattern for fixed and free factor loadings is consistent across different groups, metric invariance indicates items' factor loadings are invariant across groups (Kim et al., 2010). Results of multigroup CFA showed that the measures were cross-culturally equivalent at both configural level, $\chi^{2}(240)=436.26, \chi^{2} / d f=1.82, \mathrm{RMSEA}=.03$, SRMR $=.06$, and CFI = .97; and metric level, $\chi^{2}(260)=474.67, \chi^{2} / d f=1.83$, RMSEA = .03, $\mathrm{SRMR}=.06, \mathrm{CFI}=.96$. Therefore, the combination of the data collected from different countries in subsequent analyses was legitimate (Kim et al., 2010).

Table 1 presents the descriptive statistics and correlations of the study variables. Most measured variables were correlated to each other, with significant coefficients ranging from $r=-.09(p<.05)$ for the correlation between individualism and power distance to $r=.47(p<.001)$ for the correlation between organizational trust and organizational commitment.

Following prior researchers (e.g., Choi, Puig, Kim, Lee, \& Lee, 2014), I used regression analyses to test the main effects and the interactive effects of cultural values on trust and commitment. Table 2 presents the results of the hypothesis testing. Individualism had a negative and significant regression coefficient for both organizational trust and commitment, supporting Hypothesis la and Hypothesis $1 \mathrm{~b}$. Power distance had a positive and significant coefficient for organizational trust, but the corresponding coefficient for organization commitment was not significant; the results supported Hypothesis 2a but not Hypothesis 2b. The coefficients for mastery orientation were positive and significant when predicting organizational trust and commitment, so Hypothesis $3 \mathrm{a}$ and Hypothesis $3 \mathrm{~b}$ were supported.

As shown in Table 2, the Individualism $\times$ Mastery interaction was statistically significant in the regression for organizational trust but not significant in that for 


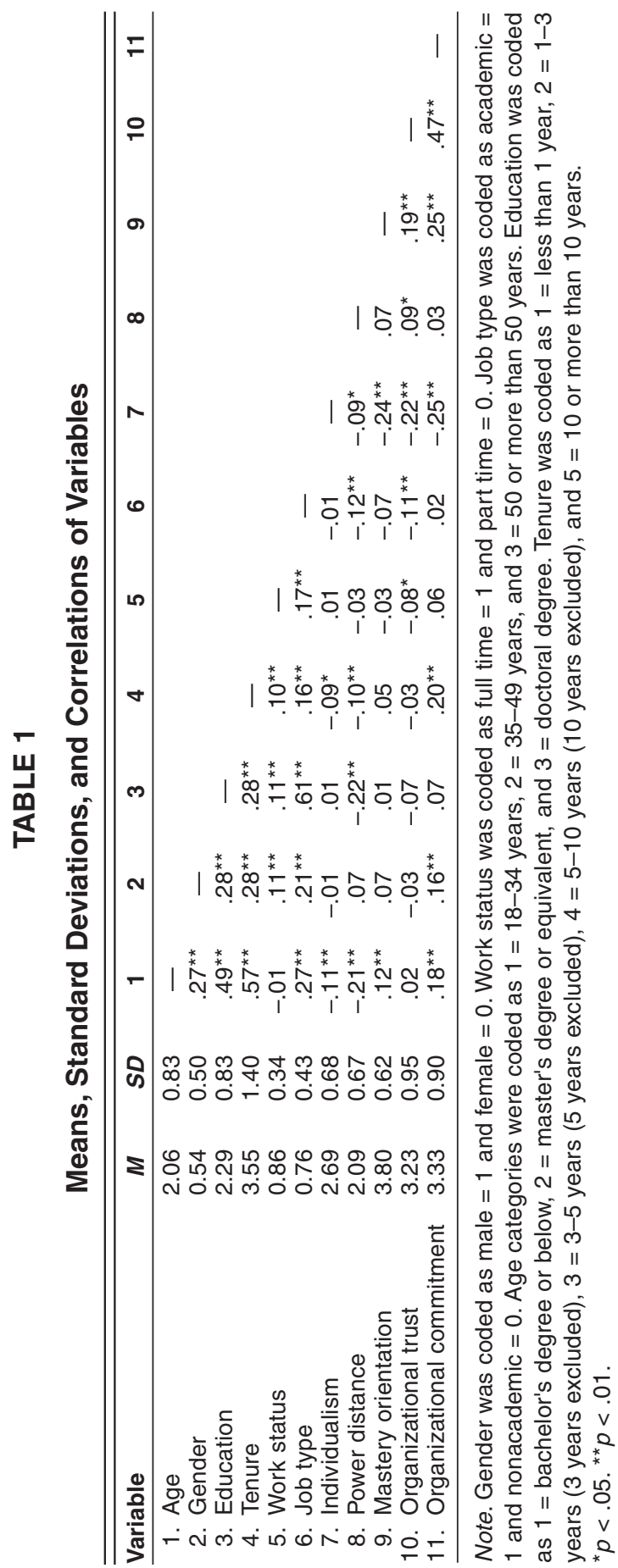




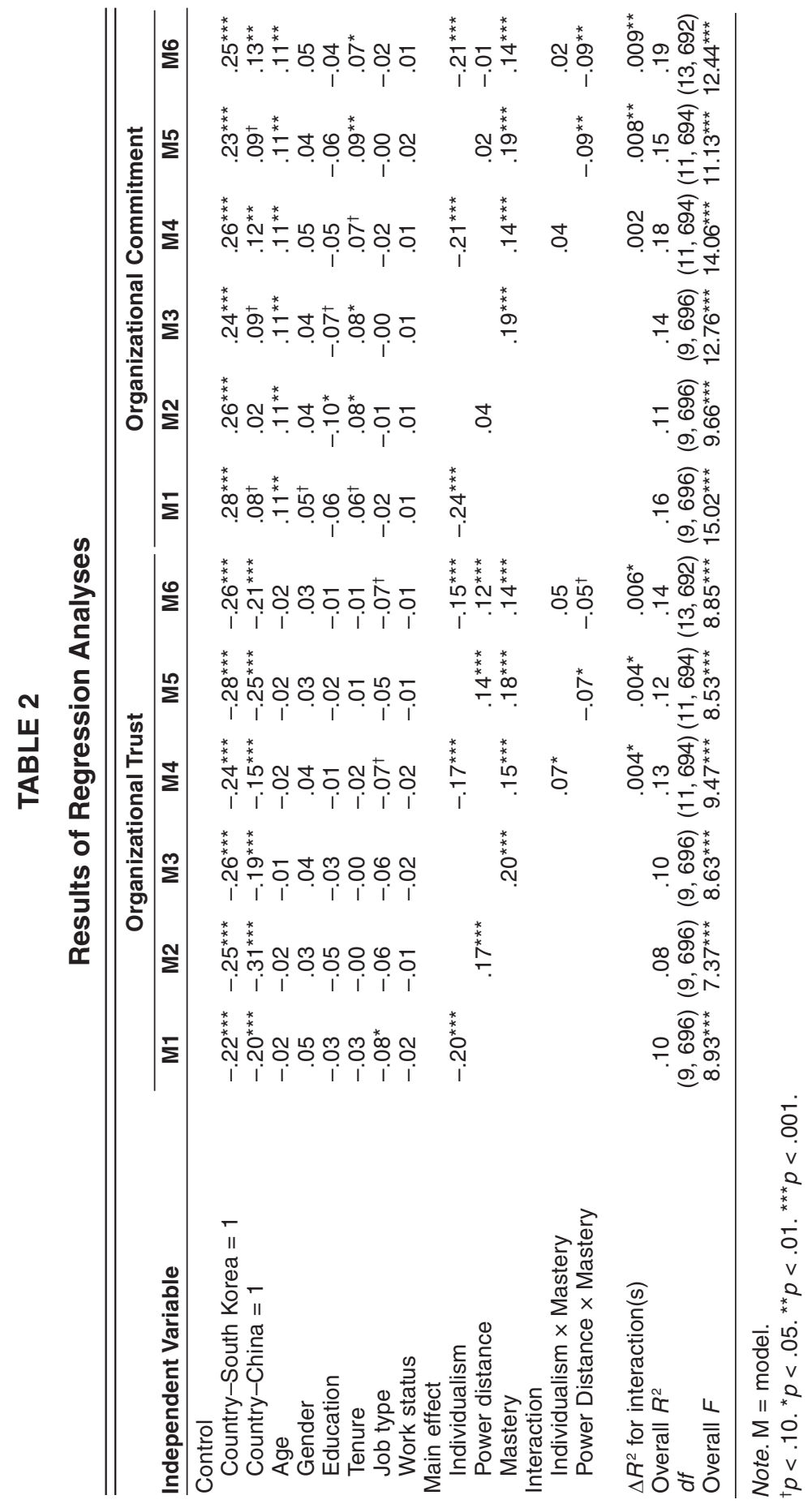


organizational commitment. As an example, Figure 1 plots the moderating effect of mastery on the relationship between individualism and organizational trust. The individualism-organizational trust relationship was stronger for individuals with low (simple slope $=-0.30, p<.001)$ than for those with high (simple slope $=-0.16$, $p<.05)$ mastery orientation. Taken together, Hypothesis 4 a was supported, but Hypothesis $4 \mathrm{~b}$ was not.

The Power Distance $\times$ Mastery interaction was statistically significant in both regressions for organizational trust and commitment, respectively. With the same procedure for the Individualism $\times$ Mastery interaction, it was found that the relationship between power distance and organizational trust was stronger for individuals with low (simple slope $=0.28, p<.001$ ) than for those with high ( .10) mastery orientation. Likewise, the power distance-commitment relationship was stronger when mastery was low (simple slope $=0.14, p<.05$ ) than when it was high (simple slope $=-0.08, n s)$. Thus, Hypothesis $5 \mathrm{a}$ and Hypothesis $5 \mathrm{~b}$ were supported.

In addition, when both interactions (Individualism $\times$ Mastery and Power Distance $\times$ Mastery) were added into the regression for organizational trust or commitment, only the Power Distance $\times$ Mastery interaction was significant. This suggested that the Power Distance $\times$ Mastery interaction effect was stronger than that of Individualism $\times$ Mastery in predicting organizational trust and commitment.

Although this study did not consider country as a focal variable in the main analysis, supplementary analyses were conducted to test the moderating role of country. Specifically, the Value $\times$ Country interaction and the Power Distance/Individualism $\times$ Mastery $\times$ Country interactions were tested to explore potential national differences. A few significant interactions reflecting West-East differences were found, and the relevant regression coefficients for interaction terms are presented as follows: The power distance-organizational trust $(\beta=.18, p<.01)$ and power distance-commitment $(\beta=.16, p<.05)$ relationships were stronger for the Chinese than for the Australian sample; the mastery-organizational trust relationship $(\beta=-.10, p<.10)$ was stronger for the Australian than for the Korean sample; the interaction effects of Power Distance $\times$ Mastery on organizational trust $(\beta=-.18, p<.05)$ and on commitment $(\beta=-.14, p<.10)$ were stronger for the Chinese than for the Australian sample; and the interaction effect of Individualism $\times$ Mastery $(\beta=-.12, p<.05)$ on organizational trust was stronger for the Korean than for the Australian sample.

\section{DISCUSSION}

This study is among the first to combine Hofstede's (1980) and Kluckhohn and Strodbeck's (1961) models to examine the effects of cultural values on employee attitudes. This approach and the current findings extend Triandis's (1993) key concepts (social group relations and environmental orientation) underlying culture to empirical studies. Specifically, employees with lower levels of individualism were found to have higher levels of organizational trust and commitment. These results are consistent with Clugston et al.'s (2000) finding that collectivism is positively associated with affective commitment, and with Doney, Cannon, and Mullen's (1998) 


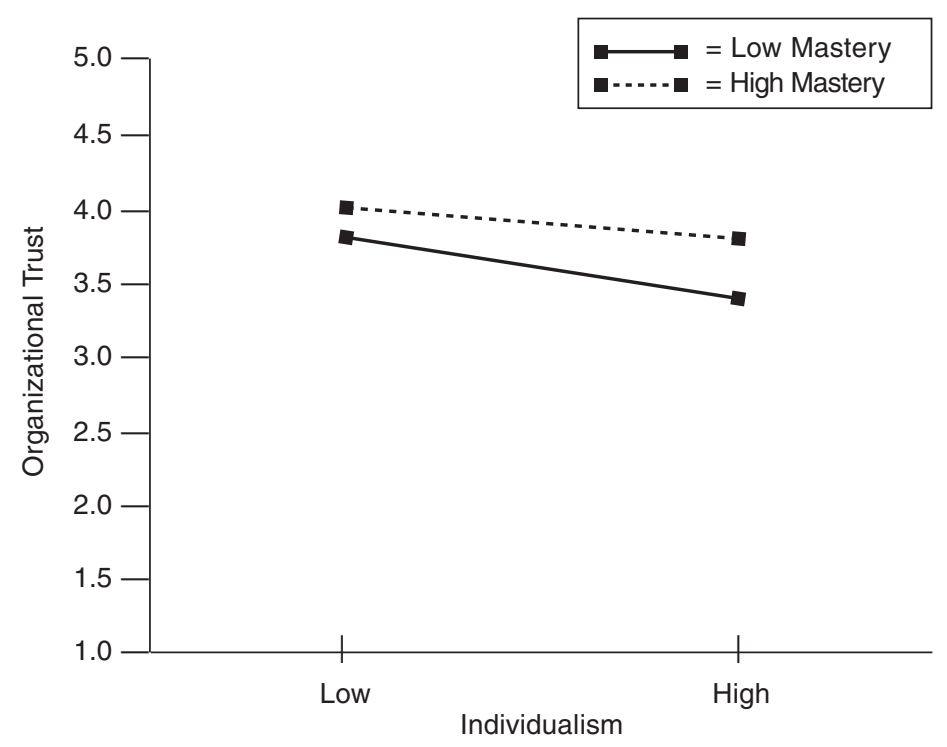

FIGURE 1

\section{The Moderating Role of Mastery in the Relationship Between Individualism and Organizational Trust}

report that collectivists, relative to individualists, are more likely to develop trust in work groups through in-group norms. Hofstede suggested that collectivists (with low individualism) distinguish in-groups from out-groups. The present findings confirm that one's work organization is likely to be identified by collectivists as an in-group (Clugston et al., 2000), although immediate and extended family appear to be even more important (Fischer \& Mansell, 2009).

In line with Ren's (2007) study, the present study did not detect a significant relationship between power distance and organizational commitment, although several cross-cultural comparisons at the country level found that power distance could explain some differences in commitment development. Because the present study focused on individual power distance orientation, this inconsistency to some extent reflects the potentially different structures of cultural value conceptualizations across individual and country levels (Fischer, Vauclair, Fontaine, \& Schwartz, 2010). However, power distance was found to significantly predict organizational trust, with higher power distance fostering higher trust. This finding accords with Doney et al.'s (1998) viewpoint that, because individuals with low power distance are less likely to conform to the prescribed norms and authority and prefer to do whatever they want, the resultant freedom of personal actions may prevent them from predicting and expecting outcomes from their employers' behaviors.

Mastery exhibited positive relationships to both organizational trust and commitment, which is a new finding in the area of cultural values and employee attitudes. Considering that mastery captures such characteristics as self-efficacy and internal 
locus of control (Jiang et al., 2015), the present results extend previous studies that identify the close relations between these characteristics and organizational trust (Liu, Siu, \& Shi, 2010) and commitment (Pillai \& Williams, 2004) to a cultural perspective. Taken together with Kirkman and Shapiro's (2001) work, which found that determinism, an opposite of mastery, negatively predicted organizational commitment, these findings strongly suggest that individuals' values related to their views about associated environments can affect their workplace attitudes. However, this conclusion needs to be further verified by more research on Kluckhohn and Strobeck's (1961) environment-related cultural orientations.

Additionally, the present study largely supports the proposition that environmentoriented values (e.g., mastery) interact with social group relations in the formation of employees' workplace attitudes. Under the condition that individuals submit to the environment and rely on outside forces, individualism and power distance tend to relate more strongly to employee attitudes—negative and positive, respectively. That is, in-group identification and an emphasis on status reflected in authority inequalities may initiate stronger positive changes in psychological states and attitudes to complement low-mastery individuals' fatalism-based beliefs and lack of self-confidence, which may result in psychological pressures, anxieties, and distress (Neff \& Hoppe, 1993). This complement appears to be less likely to occur in highmastery employees, who tend to be aggressive in directing environmental forces.

There are several limitations that need to be addressed in future research. First, the cross-sectional, single-source data may have caused common method variance (Zhao, Hwang, \& Lee, 2016). Although the CFA results suggest this variance was not significant, the statistical strategy cannot completely rule out the risk of bias in some cases. Future research should use multisource data to produce more reliable results. Second, the data collection procedures used in this study were inconsistent. Chinese participants answered a paper survey, whereas Korean and Australian participants answered an online survey. Inconsistencies in data collection resulted in significant differences in the response rates and may have also confounded the detection of some cultural value effects. Future research should use consistent methods of data collection. Third, some issues in the translation process resulted in the need to delete one item for mastery to improve the scale reliability; it is possible that the deletion of the item distorted some results. Future research should endeavor to improve the reliability and validity of multilanguage translation.

Fourth, as this study is highly exploratory, particularly in terms of the moderating role of mastery, only employee attitudes toward the organization and one environmentoriented value were examined. The exclusion of attitudes toward supervisors and coworkers makes it difficult to infer cultural value effects from more complex internal organizational social systems. Future research should consider extending the current research framework using attitudes and behaviors toward different referents and including other environment-based cultural values. Fifth, the connotations of individualism-collectivism may not have been fully reflected in this study. Although the current study followed Hofstede (1980) in considering individualism and collectivism as opposite ends on a single continuum, some researchers (e.g., Triandis, 
1993) suggest that they are independent dimensions, each consisting of horizontal and vertical categories, and that people apply different sets of values in different contexts. Future research may test whether mastery and other environment-oriented values can moderate the relationships between finer grained aspects of individualismcollectivism and employee attitudes. Finally, this study did not straightforwardly consider and hypothesize country as a key variable because of its exclusive focus on individual-level cultural values. Although supplementary analyses were conducted to incorporate country, only a few but no strong patterns were identified for national differences. Future explorations, with a more explicit addition of country and involving more countries, are warranted to generate stronger empirical evidence regarding the functional patterns of cultural value effects on employee attitudes.

Despite these limitations, the present findings carry useful practical implications for employment counseling and organizational management. Employment counselors as well as managers may have more alternatives to facilitate decision making in pre- and postemployment activities. In the preemployment phase, counselors may seek information concerning clients' value orientations when designing interventions to foresee potential difficulties in developing trust- and commitment-based relationships with future employers. For example, if a client has average levels of individualism and power distance, it would be helpful for counselors to further assess the client's orientation to control over his or her surroundings. Certainly, given the highly exploratory nature of the current study, these potential practices need to be complemented by the consideration of the client's other attributes and associated circumstances. Similar strategies may also be applicable to employers. The findings suggest that during the recruitment process, when the employer has not much knowledge of the candidates, managers may, in addition to relying on the known strategies (e.g., making initial predictions of employees' trust in and commitment to the organization based on their individualism and power distance orientations), have the option of considering candidates' mastery orientation.

In the postemployment phase, the trust and commitment employees develop toward their employers are likely associated with positive and comfortable feelings, because the presence of these affectively relevant attitudes always implies that few psychological obstacles or conflicts exist in the workplace (Koopman, Lanaj, \& Scott, 2016). It should be noted that, in many cases, employment counselors, particularly external counselors, may not be able to control or direct the situational factors that may confound employees' trust and commitment, although some counselors employed by the organization can report such issues and propose recommendations. However, counselors can still analyze the value-related factors that may affect employees themselves regarding trust and commitment development. For example, when external factors are excluded, analyzing individual value orientations may lead counselors to correctly identify some internally inherent reasons that prevent employees from developing effective trust- and commitment-based relationships in the workplace (Ramamoorthy, Kulkarni, Gupta, \& Flood, 2007). From the management perspective, in this phase, managers are more familiar with various aspects of their employees, including their value orientations, and thus may reinforce the positive effects of value 
orientations on employee attitudes using practices aligned with the organizational climate. For example, if the organization values collectivism (low individualism), managers may reinforce the role of collectivism in promoting trust and commitment by deliberately adjusting employees' mastery orientation to a lower level. Because value orientations may be resistant to change, what managers can do in this case is to openly emphasize that employees not excessively attempt to exert control over, but be humble and keep harmonious relationships with, their immediate workplace surroundings. This method of reinforcement may, to a certain extent, raise employees' awareness of their mastery-related values and lead them to reflect on those values, although it may not produce immediate effects. More in-depth practical implications need to be drawn from future studies to further explore issues related to values and employee outcomes.

\section{REFERENCES}

Allen, N. J., \& Meyer, J. P. (1990). The measurement and antecedents of affective, continuance and normative commitment to the organization. Journal of Occupational Psychology, 63, 1-18.

Armstrong, J. S., \& Overton, T. S. (1977). Estimating nonresponse bias in mail surveys. Journal of Marketing Research, 14, 396-402.

Aryee, S., Budhwar, P. S., \& Chen, Z. X. (2002). Trust as a mediator of the relationship between organizational justice and work outcomes: Test of a social exchange model. Journal of Organizational Behavior, 23, 267-285.

Botero, I. C., \& Van Dyne, L. (2009). Employee voice behavior interactive effects of LMX and power distance in the United States and Colombia. Management Communication Quarterly, 23, 84-104.

Boyacigiller, N. A., \& Adler, N. J. (1991). The parochial dinosaur: Organizational science in a global context. Academy of Management Review, 16, 262-290.

Brislin, R. W. (1980). Translation and content analysis of oral and written materials. In H. C. Triandis \& J. W. Berry (Eds.), Handbook of cross-cultural psychology (Vol. 2, pp. 389-444). Boston, MA: Allyn $\&$ Bacon.

Brooke, P. P., Russell, D. W., \& Price, J. L. (1988). Discriminant validation of measures of job satisfaction, job involvement, and organizational commitment. Journal of Applied Psychology, 73, 139-145.

Chathoth, P. K., Mak, B., Sim, J., Jauhari, V., \& Manaktola, K. (2011). Assessing dimensions of organizational trust across cultures: A comparative analysis of US and Indian full service hotels. International Journal of Hospitality Management, 30, 233-242.

Chatterton, P. (2000). The cultural role of universities in the community: Revisiting the universitycommunity debate. Environment and Planning, 32, 165-182.

Choi, H., Puig, A., Kim, K., Lee, S., \& Lee, S. M. (2014). Examining differential effects of internal and external resources on counselor burnout symptoms in South Korea. Journal of Employment Counseling, 51, 2-15. doi:10.1002/j.2161-1920.2014.00037.x

Clugston, M., Howell, J. P., \& Dorfman, P. W. (2000). Does cultural socialization predict multiple bases and foci of commitment? Journal of Management, 26, 5-30.

Colquitt, J. A., Scott, B. A., \& LePine, J. A. (2007). Trust, trustworthiness, and trust propensity: A metaanalytic test of their unique relationships with risk taking and job performance. Journal of Applied Psychology, 92, 909-927.

Colquitt, J. A., Scott, B. A., Rodell, J. B., Long, D. M., Zapata, C. P., Conlon, D. E., \& Wesson, M. J. (2013). Justice at the millennium, a decade later: A meta-analytic test of social exchange and affectbased perspectives. Journal of Applied Psychology, 98, 199-236.

Doney, P. M., Cannon, J. P., \& Mullen, M. R. (1998). Understanding the influence of national culture on the development of trust. Academy of Management Review, 23, 601-620. 
Dorfman, P. W., \& Howell, J. P. (1988). Dimensions of national culture and effective leadership patterns: Hofstede revisited. Advances in International Comparative Management, 3, 127-150.

Evanschitzky, H., Iyer, G. R., Plassmann, H., Niessing, J., \& Meffert, H. (2006). The relative strength of affective commitment in securing loyalty in service relationships. Journal of Business Research, 59, 1207-1213.

Farh, J. L., Hackett, R. D., \& Liang, J. (2007). Individual-level cultural values as moderators of perceived organizational support-employee outcome relationships in China: Comparing the effects of power distance and traditionality. Academy of Management Journal, 50, 715-729.

Finch, M. D., Shanahan, M. J., Mortimer, J. T., \& Ryu, S. (1991). Work experience and control orientation in adolescence. American Sociological Review, 56, 597-611. doi:10.2307/2096082

Fischer, R., \& Mansell, A. (2009). Commitment across cultures: A meta-analytical approach. Journal of International Business Studies, 40, 1339-1358.

Fischer, R., Vauclair, C. M., Fontaine, J. R. J., \& Schwartz, S. H. (2010). Are individual-level and country-level value structures different? Testing Hofstede's legacy with the Schwartz Value Survey. Journal of Cross-Cultural Psychology, 41, 135-151.

Gabarro, J. J., \& Athos, J. (1976). Interpersonal relations and communications. Englewood Cliffs, NJ: Prentice-Hall.

Gelfand, M. J., Erez, M., \& Aycan, Z. (2007). Cross-cultural organizational behavior. Annual Review of Psychology, 58, 479-514.

Hofstede, G. (1980). Culture's consequences: International differences in work-related values. Beverly Hills, CA: Sage.

Hofstede, G., \& Bond, M. H. (1988). The Confucius connection: From cultural roots to economic growth. Organizational Dynamics, 16, 4-21.

Hofstetter, H., \& Cohen, A. (2014). The mediating role of job content plateau on the relationship between work experience characteristics and early retirement and turnover intentions. Personnel Review, 43, 350-376.

House, R. J., Hanges, P. J., Javidan, M., Dorfman, P. W., \& Gupta, V. (2004). Culture, leadership, and organizations: The globe study of 62 societies. Thousand Oaks, CA: Sage.

Israel, G. D. (1992). Determining sample size. Gainesville: University of Florida, Cooperative Extension Service, Institute of Food and Agriculture Sciences.

Jiang, Z. (2015). Core self-evaluation and career decision self-efficacy: A mediation model of value orientations. Personality and Individual Differences, 86, 450-454.

Jiang, Z., Gollan, P. J., \& Brooks, G. (2015). Moderation of doing and mastery orientations in relationships among justice, commitment, and trust: A cross-cultural perspective. Cross Cultural Management: An International Journal, 22, 42-67.

Kim, T. Y., Weber, T. J., Leung, K., \& Muramoto, Y. (2010). Perceived fairness of pay: The importance of task versus maintenance inputs in Japan, South Korea, and Hong Kong. Management and Organization Review, 6, 31-54.

Kirkman, B. L., Lowe, K. B., \& Gibson, C. B. (2006). A quarter century of culture's consequences: A review of empirical research incorporating Hofstede's cultural values framework. Journal of International Business Studies, 37, 285-320.

Kirkman, B. L., \& Shapiro, D. L. (2001). The impact of cultural values on job satisfaction and organizational commitment in self-managing work teams: The mediating role of employee resistance. Academy of Management Journal, 44, 557-569.

Kline, R. B. (2010). Principles and practice of structural equation modeling (3rd ed.). New York, NY: Guilford Press.

Kluckhohn, F. R., \& Strodtbeck, F. L. (1961). Variations in value orientations. Evanston, IL: Row, Peterson.

Koller, M. (1988). Risk as a determinant of trust. Basic \& Applied Social Psychology, 9, 265-276.

Koopman, J., Lanaj, K., \& Scott, B. A. (2016). Integrating the bright and dark sides of OCB: A daily investigation of the benefits and costs of helping others. Academy of Management Journal, 59, 414-435.

Lederer, A. L., Maupin, D. J., Sena, M. P., \& Zhuang, Y. (2000). The technology acceptance model and the World Wide Web. Decision Support Systems, 29, 269-282.

Li, Y., Chen, H., Liu, Y., \& Peng, M. W. (2014). Managerial ties, organizational learning, and opportunity capture: A social capital perspective. Asia Pacific Journal of Management, 31, 271-291. 
Liu, J., Siu, O.-L., \& Shi, K. (2010). Transformational leadership and employee well-being: The mediating role of trust in the leader and self-efficacy. Applied Psychology, 59, 454-479. doi:10.1111/j.14640597.2009.00407.x

Lysaker, P. H., Erickson, M., Ringer, J., Buck, K. D., Semerari, A., Carcione, A., \& Dimaggio, G. (2011). Metacognition in schizophrenia: The relationship of mastery to coping, insight, self-esteem, social anxiety, and various facets of neurocognition. British Journal of Clinical Psychology, 50, 412-424.

Lytle, A., Brett, J., Barsness, Z., Tinsley, C., \& Janssens, M. (1995). A paradigm for confirmatory crosscultural research in organizational behavior. Research in Organizational Behavior, 17, 167-214.

Maznevski, M. L., \& DiStefano, J. J. (1995). Measuring culture in international management: The Cultural Perspectives Questionnaire. In The University of Western Ontario working paper series (pp. 95-120). London, Ontario, Canada: University of Western Ontario.

Maznevski, M. L., Gomez, C. B., DiStefano, J. J., Noorderhaven, N. G., \& Wu, P. C. (2002). Cultural dimensions at the individual level of analysis. International Journal of Cross Cultural Management, 2, 275-295.

Meglino, B. M., \& Ravlin, E. C. (1998). Individual values in organizations: Concepts, controversies, and research. Journal of Management, 24, 351-389.

Meyer, J. P., Allen, N. J., \& Smith, C. A. (1993). Commitment to organizations and occupations: Extension and test of a three-component conceptualization. Journal of Applied Psychology, 78, 538-551.

Neff, J. A., \& Hoppe, S. K. (1993). Race/ethnicity, acculturation, and psychological distress: Fatalism and religiosity as cultural resources. Journal of Community Psychology, 21, 3-20.

Parente, R. C., Baack, D. W., \& Hahn, E. D. (2011). The effect of supply chain integration, modular production, and cultural distance on new product development: A dynamic capabilities approach. Journal of International Management, 17, 278-290. doi:10.1016/j.intman.2011.08.001

Pillai, R., \& Williams, E. A. (2004). Transformational leadership, self-efficacy, group cohesiveness, commitment, and performance. Journal of Organizational Change Management, 17, 144-159.

Podsakoff, P. M., MacKenzie, S. B., Lee, J. Y., \& Podsakoff, N. P. (2003). Common method biases in behavioral research: A critical review of the literature and recommended remedies. Journal of Applied Psychology, 88, 879-903.

Ramamoorthy, N., Kulkarni, S. P., Gupta, A., \& Flood, P. C. (2007). Individualism-collectivism orientation and employee attitudes: A comparison of employees from the high-technology sector in India and Ireland. Journal of International Management, 13, 187-203.

Randall, D. M. (1993). Cross-cultural research on organizational commitment: A review and application of Hofstede's value survey module. Journal of Business Research, 26, 91-110.

Ren, R. (2007). Quality of supervisor-subordinate relationship, cultural values, and organizational justice (Doctoral dissertation). Texas A\&M University, College Station, TX. Retrieved from ProQuest Dissertation \& Theses database. (UMI No. 3296523)

Robinson, S. L. (1996). Trust and breach of the psychological contract. Administrative Science Quarterly, 41, 574-599.

Schilpzand, M. C., Martins, L. L., Kirkman, B. L., Lowe, K. B., \& Chen, Z. X. (2013). The relationship between organizational justice and organizational citizenship behavior: The role of cultural value orientations. Management and Organization Review, 9, 345-374.

Schoorman, F. D., Mayer, R. C., \& Davis, J. H. (2007). An integrative model of organizational trust: Past, present, and future. Academy of Management Review, 32, 344-354.

Schwartz, S. H. (1992). Universals in the content and structure of values: Theoretical advances and empirical tests in 20 countries. In M. Zanna (Ed.), Advances in experimental social psychology (Vol. 25, pp. 1-65). New York, NY: Academic Press.

Shao, R., Rupp, D. E., Skarlicki, D. P., \& Jones, K. S. (2013). Employee justice across cultures: A metaanalytic review. Journal of Management, 39, 263-301.

Shih, T. H., \& Fan, X. (2008). Comparing response rates from web and mail surveys: A meta-analysis. Field Methods, 20, 249-271.

Sivakumar, K., \& Nakata, C. (2001). The stampede toward Hofstede's framework: Avoiding the sample design pit in cross-cultural research. Journal of International Business Studies, 32, 555-574. doi:10.2307/3069497 
Taras, V., Kirkman, B. L., \& Steel, P. (2010). Examining the impact of culture's consequences: A threedecade, multilevel, meta-analytic review of Hofstede's cultural value dimensions. Journal of Applied Psychology, 95, 405-439.

Tett, R. P., \& Burnett, D. D. (2003). A personality trait-based interactionist model of job performance. Journal of Applied Psychology, 88, 500-517.

Triandis, H. C. (1993). Collectivism and individualism as cultural syndromes. Cross-Cultural Research, $27,155-180$.

Yeganeh, H., \& Su, Z. (2011). The effects of cultural orientations on preferred compensation policies. The International Journal of Human Resource Management, 22, 2609-2628.

Zhao, X., Hwang, B.-G., \& Lee, H. N. (2016). Identifying critical leadership styles of project managers for green building projects. International Journal of Construction Management, 16, 150-160. doi:10.1080/15623599.2015.1130602 